\title{
Resenha
}

\section{Aprendizagem baseada em cenários de prática: fronteiras, identidade e cognoscibilidade}

\author{
Learning in Landscapes of practice \\ Boundaries, identity, and knowledgeability in practice-based learning
}

\author{
Jenny Patricia Acevedo Rincón ${ }^{1}$
}

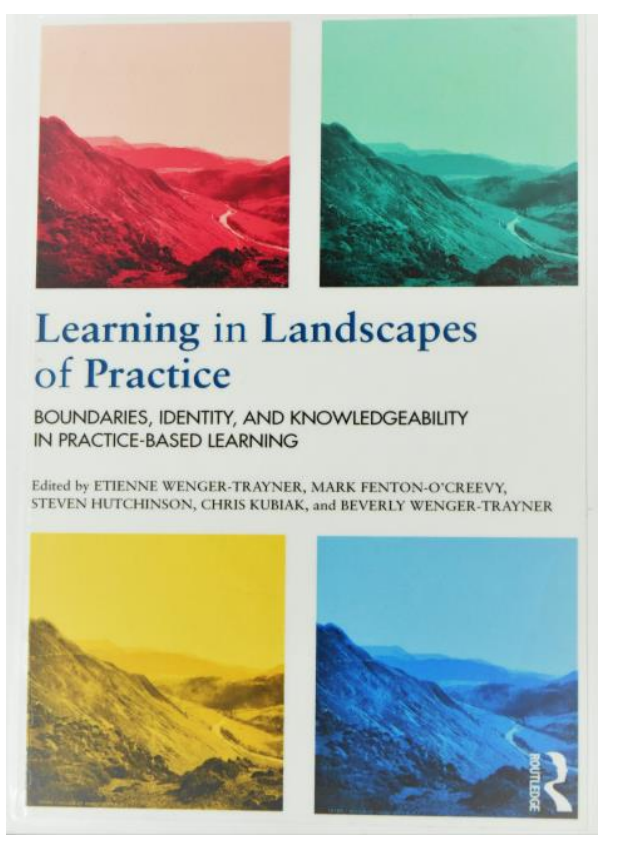

\begin{abstract}
Wenger-Trayner, E., Fenton-O'Creevy, M., Hutchinsonn, S., Kubiak, Ch., \& WengerTrayner. B. (2015). Learning in Landscapes of practice: boundaries, identity, and knowledgeability in practice-based learning. New York: Routledge.
\end{abstract}

Resumo. Este livro apresenta os conceitos de identidade, experiência profissional e aprendizagem em comunidades de prática. É um estudo pioneiro e oportuno sobre desenvolvimento profissional e ensino superior, fundamentado teoricamente na Teoria Social da Aprendizagem, incluindo contribuições de outros autores e colaboradores. O livro está organizado em quatro partes, contendo nove capítulos, e tem por objetivo apresentar diversos cenários de prática em Comunidades de Prática, sendo permeadas por múltiplas vozes deles advindas. $\mathrm{O}$ conceito de fronteira é trazido como um espaço para a aprendizagem individual e social dos participantes da comunidade, e que acontece a partir de diferentes cenários da prática.

Palavras-chave: Cenários de prática, fronteiras, identidade, cognoscibilidade.

\footnotetext{
${ }^{1}$ Doutoranda em Educação da Universidade Estadual de Campinas (FE/Unicamp), Campinas/SP, Brasil. Mestre em Docência das Matemáticas pela Universidade Pedagógica Nacional (UPN), Bogotá, Colômbia. Licenciada em Matemáticas da Universidade Industrial de Santander (UIS), Bucaramanga, Colômbia. Email: jennyacevedorincon@gmail.com.
} 
DOI: http://dx.doi.org/10.20396/zet.v25i3.8649693

Abstract. This book presents the concepts of identity, professional experience and learning in communities of practice. It is a pioneer and timely study on professional development and higher education, theoretically based on the Social Learning Theory, including contributions from other authors and people involved. The book is organized in four parts that are developed in nine chapters, aiming at presenting diverse scenarios of practice in Communities of Practice that are permeated by their multiple voices. The boundary concept is brought as a space for individual and social learning from the community participants, and that takes place from different scenarios of the practice.

Keywords: Landscape of practice, boundaries, identity, knowledgeability.

A Teoria Social de Aprendizagem (Lave \& Wenger, 1991) é a principal base de sustentação teórica deste livro. Esta teoria foi construída a partir de estudos sobre o modo como as pessoas de uma determinada comunidade aprendiam, mediante participação em comunidades de prática, sem que houvesse um sistema formal de ensino. As primeiras aplicações dessa teoria ocorreram no campo empresarial, e, depois, passou também a ser utilizada como aporte para investigar a aprendizagem docente em comunidades profissionais. No Brasil e no âmbito da Educação Matemática, alguns grupos de pesquisa têm utilizado este referencial teórico. Este é o caso, por exemplo, dos grupos de pesquisa Prática Pedagógica em Matemática (PRAPEM) e Grupo de Estudo e Pesquisa sobre Formação de Professores de Matemática (GEPFPM) da FE/Unicamp (Fiorentini, 2009 e 2013; Acevedo e Fiorentini, 2016).

O livro relativo a esta resenha traz novos elementos e compreensões sobre essa teoria e foi motivada por estudos e discussões sobre aprendizagem entre os profissionais filiados ao centro de "aprendizagem profissional baseado em práticas", da Open University Bussiness School no Reino Unido, e Etienne Wenger-Trayner e Beverly Wenger-Trayner como autores independentes. O principal autor desta obra, agora chamado Etienne Wenger-Trayner, além de criar, juntamente com Jean Lave, a Teoria Social de Aprendizagem (TSA), estudou e aprofundou, posteriormente, os temas de identidade e de cenários de práticas relativas às comunidades de prática e suas fronteiras (Wenger, 1998; 2002; 2015).

O livro é produto da participação de Etienne Wenger-Trayner em um workshop com os demais autores. No capítulo introdutório, os autores apresentam o desenvolvimento do workshop e pontuam as experiências de aprendizagem que ilustram como explorar possibilidades de aprendizagem em diferentes contextos de prática. Em particular, os exemplos exploram formas de aprendizagem de profissionais nas áreas de ensino, enfermagem, serviço social, gestão e contabilidade, sendo esses contextos constituintes de cenários de prática. Uma interação entre as fronteiras das diferentes comunidades de prática constitui-se em um convite para adentrar à leitura dos capítulos posteriores que oferecem outros exemplos para explorar e discutir os conceitos de cenários de prática e as possibilidades de aprendizagem.

O livro está dividido em quatro partes, a seguir: i) um marco referencial para o conceito de aprendizagem em cenários de práticas; ii) estórias desde os cenários de prática; iii) Empreendedores; e iv) conclusões e um convite para dar continuidade à 
DOI: http://dx.doi.org/10.20396/zet.v25i3.8649693

conversação. Estas, por sua vez, contém nove capítulos que desenvolvem amplamente o proposto em cada subdivisão.

Parte I apresenta as bases teóricas do livro: Um marco referencial para o conceito de aprendizagem em cenários de práticas, que subsidia as discussões nos capítulos posteriores. Neste capítulo, problematiza-se a complexidade do conceito body of knowledge ${ }^{2}$ no cenário das práticas sociais, no qual os autores propõem seus elementos constituintes, tais como: a política como poder das dinâmicas sociais, o plano do cenário da natureza das práticas, a diversidade dos cenários e as fronteiras entre os cenários de prática. Discutem, também, as fronteiras como potenciais lugares de aprendizagem, e introduz o termo Knowledgeabiliy ${ }^{3}$, que podemos compreender como a competência do uso de conhecimentos, e, também de aprender/produzir conhecimentos em diferentes comunidades de prática a través das práticas próprias das comunidades.

A partir disso, o capítulo apresenta a identificação e a des-identificação como parte das trajetórias de aprendizagem dentro das práticas. Destaca-se, em particular, a aprendizagem não apenas como aquisição de conhecimentos, mas também como a possibilidade do indivíduo "tornar-se uma pessoa que habita dentro do cenário com uma identidade cuja construção dinâmica reflete sobre nossas trajetórias naquele cenário" (Wenger-Trayner et al., 2015, p.19). Esse trânsito pelas/entre as práticas configura quem "nós somos". Um exemplo bastante prático é trazido para compreender o conceito de aprendizagem nas fronteiras, assim como o de identidade. Apresentam-se constantes questionamentos sobre quanto do teórico está presente e quanto resulta da interação com clientes de suas empresas de consultoria, ou vice-versa. Porém, o estudo esclarece que nem todas as práticas apontam nesta direção, mas se as relações e interações com outros dentro dos cenários de práticas motivam os participantes a consolidar sua identidade no interior das comunidades. Baseados nestes pressupostos, os autores apresentam a identidade em três formas de pertença em uma comunidade: engajamento (engagement), imaginação (imagination) e alinhamento (alignment).

A segunda parte do livro explora em quatro capítulos o tema-chave em relação aos cenários de prática por meio de histórias que acontecem dentro de prática reais. Esta segunda parte do livro começa pelo capítulo 2: Fracasso e resiliência dentro das fronteiras: O processo emocional do trabalho da identidade. Destaca-se a identidade como um atributo não individual, sendo que este é negociado de novo em cada comunidade em que participamos. A fronteira, como limite entre as comunidades, permite modular nossas identidades para cada contexto. Portanto, temos histórias de aprendizado social que carregamos conosco em cada nova situação. Como ressalta Wenger (1998), "a identidade é uma trajetória no tempo que incorpora o passado e o futuro no significado do presente" (p. 169). Neste capítulo são ilustradas três histórias para explorar a experiência de negociar a identidade em um novo cenário. Os protagonistas experimentaram situações de fracasso e compartilharam as experiências

\footnotetext{
${ }^{2}$ Corpo de conhecimento

${ }^{3}$ Cognoscibilidade
} 
DOI: http://dx.doi.org/10.20396/zet.v25i3.8649693

de suas próprias comunidades, nas quais eram altamente competentes, para outras comunidades que pretendiam ganhar aquelas competências. O trabalho emocional é envolvido dentro do trânsito pelas diferentes comunidades, assim como das diferentes identidades que se constituem. No entanto, aqueles sentimentos envolvidos, algumas vezes de sucesso e outras de fracasso nas experiências pode resultar em resistência ao investimento em identidade dentro do novo contexto. Por tanto, o trabalho emocional não é periférico à aprendizagem, é parte dele.

O capítulo 3, Estudantes na fronteira entre o acadêmico e o profissional: Turistas e hospedes em práticas baseadas em educação, apresenta exemplos nos quais a experiência de alunos na educação é baseada na prática, à medida que participam de comunidades acadêmicas e de trabalho, e outras diferentes comunidades de suas vidas profissionais. O trânsito entre as diferentes comunidades de prática cria o sentimento de estrangeiros, no sentido em que o estrangeiro permanecerá um tempo significativo na nova terra, para se adequar nela e formar uma nova identidade. Porém, esta identidade não apagará sua própria identidade. Este sentimento de estrangeria foi experimentado nas histórias exemplificadas do capítulo, no qual o trânsito entre a academia e o trabalho consolidou múltiplas identidades. Os autores escreveram sobre os desafios que enfrentaram os estudantes nessas transições, tal como aprender a desenvolver a resiliência face a estes desafios, e como eles procuram transladar a aprendizagem de uma parte do cenário para outro.

No capítulo 4, Multi-membresia em comunidades e identificação, a partir dos exemplos presentados, sugere-se uma construção multifacetada das identidades, concebendo-as como mudanças e evoluções nas práticas. Isto reflete sobre a identidade, a qual não se fragmenta, mas o indivíduo se esforça a responder às identidades já constituídas. Já no capítulo 5, o último da parte II, intitulado Mediação nos encontros de fronteira, os autores apresentam quatro histórias de intermediação. Neste capítulo, os autores reconhecem que os encontros de fronteiras não são facilmente construídos e podem apresentar possíveis desencontros e contradições. O capítulo se aprofunda nas respostas das seguintes questões: o que faz com que a mediação facilite o desenvolvimento da knowledgeability; como os objetos fronteiriços suportam os encontros de fronteiras e motivam pontos de conexão; e como a mediação constrói o legítimo nas suas atividades. Os autores destacam que o objeto de fronteira não deve ser confundido com a participação no próprio encontro fronteiriço. Apesar de possuírem objetos de fronteira bem desenvolvidos, os participantes necessitam administrar cuidadosamente o encontro fronteiriço. Além disso, podem encontrar-se em uma posição de legitimidade incerta. Os mediadores das histórias do capítulo parecem exercer considerável habilidade e determinação no estabelecimento dos encontros de fronteira e na mudança de panorama. No entanto, a sua capacidade de provocar mudanças surge sempre da ação.

$\mathrm{Na}$ parte III, Empreendedores, os autores apresentam os cenários dentro da vivência no interior das práticas. Dessa maneira, são desenvolvidos três capítulos com 
DOI: http://dx.doi.org/10.20396/zet.v25i3.8649693

exemplos particulares aos campos de dois projetos diferentes. Inicialmente, o capítulo 6 , intitulado Sistemas de empreendedores em cenários complexos, introduz o conceito de convocador de sistemas e suas conexões com a teoria. Este capítulo apresenta as vozes de dois empreendedores que exploraram os desafios das mudanças no interior das diferentes práticas, sendo o tema base do escrito dos capítulos o cultivo das comunidades de prática, as práticas e suas fronteiras.

Os dois capítulos seguintes descrevem como esses desafios foram abordados em dois grandes projetos: i) O Habitaforum: Empreendedores interessados em reinventar o planejamento do espaço, e ii) A parceria IDEA: aprendizagem de empreendedores no interior de cenários complexos na educação especial. Estes projetos são usados para explicar o conceito de Comunidade de Prática $(\mathrm{CoP})$ na estrutura do cenário, as práticas e suas fronteiras. Neste sentido, as comunidades de prática são as formas em que se constituem os convocadores de novas parcerias de aprendizagem, que criam novas capacidades e permitem novas identidades no interior dos cenários. As histórias desses projetos são contadas a partir das perspectivas dos cenários complexos.

A quarta e última parte apresenta as reflexões, implicações e conclusões sobre a aprendizagem baseada na prática, que redundam em questões mais amplas sobre o ensino superior, a aprendizagem ao longo da vida, a empregabilidade, a avaliação e o papel da universidade. Novos cenários foram contemplados neste livro, a universidade, lugares emergentes no estilo MOOC (cursos online massivos e abertos), formação massiva em conferências, através das quais as experiências relatadas contavam as histórias que residem por trás da realidade dos participantes. Cenários que mobilizaram diferentes aprendizagens, e que revelaram identidades constituídas no trânsito ao longo do tempo. Por fim, os autores fazem um convite para dar continuidade à conversação proposta no capítulo. Em síntese, este último capítulo traz as propostas de mudanças para práticas baseadas em educação. O conceito de fronteira se consolida neste livro como zona de desequilíbrio e de aprendizagem.

Finalmente, cabe dizer que esta obra cumpre com o objetivo de apresentar uma visão geral dos cenários de prática, sobretudo em relação à formação de múltiplas identidades de participantes que transitam por diferentes comunidades de prática. Este livro, portanto, pode ser útil para projetar e compreender processos de aprendizagem docente, de desenvolvimento profissional e de constituição de identidade de professores, de futuros professores, bem como de pesquisadores que participam de várias comunidades, principalmente aquelas voltadas à formação docente, às práticas profissionais ou investigativas.

Em relação aos avanços da Teoria Social da Aprendizagem, conforme anunciado por Omidvar1 e Kislov (2013), esta obra recente de Wenger-Trayner e colaboradores deixa evidente que a aprendizagem encontra um lugar na complexidade do sentido de corpo de conhecimento nas práticas sociais. Os autores retornam ao conceito de aprendizagem do indivíduo, e o situam no trânsito entre as fronteiras das comunidades, 
DOI: http://dx.doi.org/10.20396/zet.v25i3.8649693

sendo este um lugar de aprendizagem que transforma e molda a identidade de uma pessoa no interior de uma CoP. Por outra parte, nesta ocasião, são apresentados diferentes exemplos de como as comunidades de prática são analisadas na educação superior, ao proporem espaços outros, como a aprendizagem informal dos ambientes virtuais de aprendizagem. Isto é, os cenários de prática oferecidos por espaços virtuais e ambientes informais de aprendizagem são apresentados como complexos cenários de prática, não apenas como um lugar de (re) produção de conhecimento (ensinado), mas também de construção de novas práticas educativas e novas formas de aprendizagem.

\section{Referências}

Acevedo, J., \& Fiorentini, D. (2016). Práticas na formação dos licenciados em matemáticas: a experiência de uma prática interdisciplinar. Tecné, Epistemé \& Didaxis-TED, 40 (2), 129-147.

Fiorentini, D. (2009). Quando acadêmicos da universidade e professores da escola básica constituem uma Comunidade de Prática reflexiva e investigativa. In $\mathrm{D}$. Fiorentini, R. C. Grando \& R. G. S. Miskulin (Eds.), Práticas de formação e de pesquisa de professores que ensinam matemática (pp. 233-255). Campinas: Mercado de Letras.

Fiorentini, D. (2013). Learning and Professional Development of the Mathematics Teacher in Research Communities. Sisyphus - Journal of Education, 1(3), 152-181.

Lave, J., \& Wenger, E. (1991). Situated learning. Legitimate peripheral participation. United Kingdom: Cambridge University Press.

Omidvar1, O., \& Kislov, R. (2013). The Evolution of the Communities of Practice Approach: Toward Knowledgeability in a Landscape of Practice-An Interview with Etienne Wenger-Trayner. Journal of Management Inquiry, 23(3), 266-275.

Wenger, E. (1998). Communities of practice. Learning, Meaning and identity. Cambridge: Cambridge University Press.

Wenger, E., McDermott, R., \& Snyder, W. (2002). Cultivating communities of practice. A guide to managing knowledge. Massachusetts: Harvard Business School Press.

Wenger-Trayner, E., Fenton-O'Creevy, M., Hutchinsonn, S., Kubiak, Ch., \& WengerTrayner, B. (2015). Learning in Landscapes of practice: boundaries, identity, and knowledgeability in practice-based learning. New York: Routledge. 